\title{
FUNCIÓN SIMBÓLICO-POÉTICA DEL MANÁ EN EL AUTO SACRAMENTAL DE CALDERÓN
}

\author{
Enrique Rull \\ UNED \\ [Anuario calderoniano (ISSN: 1888-8046), 2, 2009, pp. 245-261]
}

El motivo del maná configura la realidad de varios autos calderonianos ${ }^{1}$, pero es en uno de ellos donde de verdad adquiere un simbolismo poético sostenido y eficaz: La piel de Gedeón. Además, como veremos, vertebra perfectamente su unidad literaria y su forma compositiva. La piel de Gedeón data de $1650^{2}$, y refleja la primera madurez del autor, cuando no solo es capaz de recrear una alegoría con suma habilidad sino además dejarla transida de caracteres narrativos y poéticos en perfecta armonía con aquella. Se trata de una obra en la que los elementos bíblicos conforman la trama argumental, que procede inequívocamente del libro de los Jueces (6-7) en lo que se refiere a la narración principal, o episodios de la vida de Gedeón, mientras que en el motivo del maná, tratado de compleja forma alegórica, procede de Éxodo (16). Naturalmente que este último motivo no aparece en

${ }^{1}$ Ver Arellano, 2000, p. 142.

${ }^{2}$ Para todos los pormenores puede verse la excelente edición de Ana Armendáriz (1998). 
la historia original de Gedeón, sino que es una incorporación a la historia basándose en el episodio del vellocino, sobre el que, como prueba de la autenticidad de su elección, Gedeón pide al ángel que haga caer sobre él el rocío de la mañana. Es pues una identificación intencionada del rocío con el maná.

La historia lineal de Gedeón en el auto está penetrada de varios elementos de perspectiva ${ }^{3}$, que pueden reducirse fundamentalmente a dos esenciales: las visiones y los sueños. Ambos, es cierto, son de tradición bíblica, pero Calderón los organiza, multiplica y distribuye en la acción del auto, de manera que van creando unos soportes dramáticos sobre los que se sustenta la historia y su función alegórica.

Por otra parte, sobre esa acción "histórica», el dramaturgo introduce una serie de secuencias puramente dramáticas por medio de las cuales reorganiza esa acción, de la misma manera que crea varias personificaciones alegóricas, tales como la Idolatría y la Aurora, el Monte, el Prado y la Mies. No es que estos personajes estén deslindados de la mencionada acción, sino que, unidos a ella, forman el conjunto alegórico-historial que es el fundamento de la obra misma ${ }^{4}$. Según esto, y siguiendo el esquema de la comedia nueva y de muchos autos, la acción comienza por una agitada escena en la que Madián y Amalec llaman al arma a los suyos, mientras, simultáneamente, la Música clama piedad. La escena, muy breve, es, un arranque muy teatral, en la que intervienen dos elementos que podríamos considerar contrapuestos, música de cajas y trompetas, de un lado, y de otro, «instrumentos de música» sin especificar, aunque, debido a la inicial observación acerca del uso de instrumentos esencialmente bélicos, hay que pensar que estos "de música» son acordados y suaves (quizá de cuerda y maderas, fundamentalmente chirimías). Pero es la secuencia que sigue, como verdadero contrapunto, la que proporciona un notable avance semántico del texto, secuencia en la que Calderón presenta a un Ángel expulsando a la Idolatría del pueblo de Israel, como causante de los males de este; mientras tanto resuenan simultáneamente las violentas voces de Amalec y los suyos, y la propia Música clama

3 Para las cuestiones relacionadas con la estructura de perspectiva puede verse Rull, 2004, pp. 360-378.

${ }^{4}$ Sobre el concepto de "historial» y "alegórico» en los autos calderonianos ya escribió A. A. Parker páginas bastante clarificadoras (1983, pp. 147 y ss.). Una puesta al día de la cuestión puede verse, sobre todo, en Arellano, 2001, pp. 103 y ss. 
misericordia. Y ya tenemos seguidamente una de esas "visiones», la primera de las que hablábamos, sobre las que se asienta la estructura de la composición.

Después del golpe de efecto que significa la irrupción de la escena violenta con la que se inicia el auto, ahora dos personajes, el Ángel y la Idolatría, abren, como en un pórtico, la acción futura a modo de «visión». Esta "visión» es muy importante, tanto desde el punto de vista doctrinal como (lo que nos interesa ahora) estructural. El Ángel presenta a la Idolatría un «teatro» del mundo en el que se van a hacer «dos representaciones / a las edades futuras». Estas dos representaciones serán, como el mismo autor dice, la primera de sombras y la segunda de luces. Pero el Ángel no solo presenta a la Idolatría ese teatro, que veremos nosotros representar, sino que previamente hará mención de cuantos símbolos pudiera encerrar el sacramento que anuncia, como la escala de Jacob y el blanco rocío, desechándolos por parecerle cosas ya acontecidas. Así, hará contemplar a la Idolatría un paisaje de nubes, montes, corderos y mieses, es decir, elementos de la naturaleza que contienen rasgos de la Encarnación, a partir de los cuales se desarrollará ese teatro de doble representación: sombras de la historia de Israel en el episodio de Gedeón, y luces en la significación eucarística de toda esa misma realidad. Precisamente esa historia de Gedeón es la que se va a desenvolver desde este momento. Cambiará el escenario y veremos al protagonista de labrador preguntándose por el misterio que hay en la limpieza del grano, cuando se le aparece un Ángel, quien le anima a rebelarse contra la dominación de los madianitas. Esta aparición o "visión» guarda un evidente correlato con la aparición del Ángel a la Idolatría para enseñarle los teatros del mundo. Uno será precisamente el de la vida de Gedeón, que actualiza ahora. Estas visiones de teatros dentro del teatro suponen la creación de una perspectiva múltiple que revela la ilusión de espacios que salen del marco del cuadro, ilusión plenamente barroca en consonancia con la pintura, la escultura y la arquitectura de la época (por ejemplo, los cuadros de Rubens, los relieves de los retablos eclesiales o la estructura de algunas catedrales) y con la música posterior (por ejemplo de los oratorios händelianos). Los volúmenes pugnan por crear una violenta perspectiva que rompa las líneas simples del escenario, los planos sin realce, para llegar al espectador en una sucesión de relieves provocadores, retablos vivos cuyas figuras se muevan fuera del marco en el 
que nacieron ${ }^{5}$. Esto se observa muy claramente en la tercera visión que se ofrece al espectador, interpenetrada de elementos nuevos de perspectivas secundarias, que enriquecen el plano lineal de la acción hasta puntos de complicación y complejidad ciertamente destacables.

De esta manera, la tercera visión o perspectiva fundamental desde la que nuevamente un personaje (y el espectador), atisban la realidad de la escena, tiene lugar tras la elección de Gedeón como caudillo por los israelitas, y la revelación que hace de este hecho la Idolatría a los madianitas, revestida de hermosísima dama. Los episodios de un campamento a otro se suceden. Las apariciones de la Idolatría, ya dirigiéndose a los madianitas, ya haciendo de espía, crean esa nueva dimensión perspectivística de la que hablamos. Y en este sentido este personaje cobra un vigor dramático como ninguno en el auto, en tanto en cuanto es el que sirve de "punto de vista» desde el que contemplar la realidad. El otro es el Ángel, que es quien se la muestra, y un tercero (más que personaje, actante o función dramática), como tendremos ocasión de ver, es el sueño. Así, la Idolatría observará cómo Gedeón lleva un blanco vellón que consagra a Dios. Lo curioso es que en esta ofrenda Calderón vuelve a crear una nueva dimensión de perspectiva, pues Gedeón mantiene un diálogo con la Música, que ahora es la «Voz» de Dios:

Gedeón

Pues siendo así

que de vos favorecido

con auxilios me asistís,

este cándido vellón,

tan de nieve que temí

que al tocarle, entre las manos

se había de derretir,

Va subiendo al monte.

esta pura piel, tan pura,

que no la podrá argüir

de átomo de mancha en ella

el ingenio más sutil,

\footnotetext{
5 Para todo lo relativo al «desbordamiento expresivo» del arte barroco sigue siendo imprescindible la lectura del libro de Emilio Orozco Díaz, El teatro y la teatralidad del Barroco, 1969; e igualmente su artículo, «Sentido de continuidad espacial y desbordamiento expresivo en el teatro de Calderón. El soliloquio y el aparte», 1983.
} 
sobre esta piedra os consagro

temeroso hasta inferir

si os ofendo en esto.

Música

No.

GEDEÓN

¿Dais os por servido?

MÚSICA

Sí.

GEDEÓN

Pues en esa confianza, si he de vencer, permitid, que en prendas de la victoria

halle, Señor, al reír

del alba en ella cuajado

sin que se llegue a esparcir

a otra parte su rocío:

esta es la señal que aquí

os pido, ¿es injusta?

MÚSICA

No.

GEDEÓN

¿Concederéismela?

MÚSICA

$\mathrm{Si}^{6}$.

Aquí está el núcleo argumental del auto, con el temor reverencial de Gedeón a Dios, y las respuestas de éste en la escena, escuetas, con monosílabos, pues la voz de Dios no debe apenas dejar traslucir emociones ni, por tanto, modulaciones de la palabra, puramente humanas. Naturalmente que esta perspectiva no es visual tanto como sonora, pues la imagen de la Música, o Dios, no se percibe, sino solo la voz. Recordemos que Dios es el Verbo, la palabra por esencia, y por eso, la palabra consonantada (la música), puesto que su voz es la ordenadora del universo, es la más adecuada para representarle.

Nuevamente, otro punto de inflexión en el relato, el cuarto, tendrá lugar con una nueva visión de la Idolatría, (indicada por el Ángel, y explicada por la voz de la Música), cuando observa cómo cae el maná sobre el vellón, en la conocida prueba que pide Gedeón a Dios de haber sido él elegido para la salvación de Israel, punto que nos abrirá otra puerta a otro plano de trasmundo, el cual viene descrito de forma detallada por esta hermosa y reveladora didascalia explícita:

${ }^{6}$ Calderón de la Barca, La piel de Gedeón, pp. 129-130, vv. 859-883. 
[Pájaros dentro]. Ábrense las cuatro nubes. En la primera está la Aurora, con manto azul y corona de flores; en la segunda la Mies, con guirnalda de espigas; en la tercera el Monte, con un árbol en la mano; en la cuarta el Prado, con un cordero. Si se pudieren ajustar los vestidos, la Mies ha de tener manto dorado, el Monte pardo, el Prado verde. Adviértese que sola la nube del vellón ha de estar lloviendo unos copos de algodón ${ }^{7}$.

Téngase en cuenta la dimensión desde la que se sitúa la Aurora, el cielo, como representante dual del fenómeno mitológico y meteorológico y como símbolo de la Virgen, una dimensión esencialmente jerárquica, como sabemos que lo es cualquier perspectiva vertical ${ }^{8}$. Ni qué decir tiene que todos los atuendos de los distintos personajes son puramente simbólicos, lo mismo que los colores respectivos, y que toda la imagen de la nube lloviendo los copos de algodón sobre el vellón no es sino la prefiguración de la eucaristía y su efecto maravilloso como alimento de vida, semejante al maná del Antiguo Testamento:

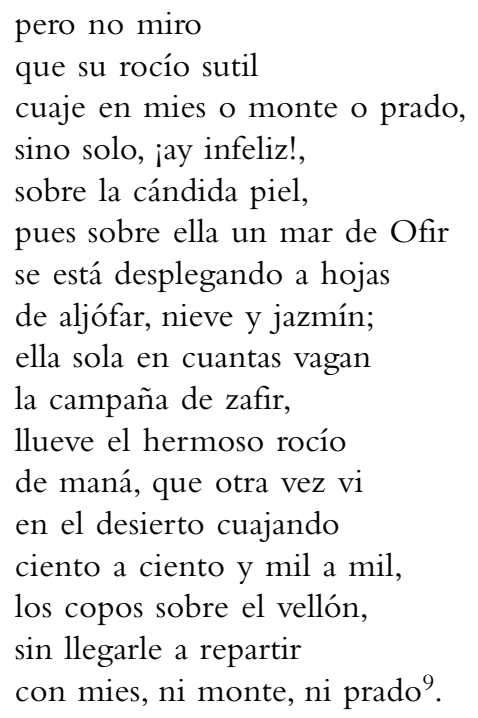

7 Calderón de la Barca, La piel de Gedeón, p. 134.

${ }^{8}$ Bachelard, 1958, pp. 20-21.

${ }^{9}$ Calderón de la Barca, La piel de Gedeón, vv. 930-946, pp. 135-136. 
La apoteosis de la escena surge cuando el Ángel se arrodilla ante la Aurora (símbolo de la Virgen) y la Música dice:

\author{
Este, no manchada piel, \\ es el rocío feliz, \\ que nadie, sino esta sola \\ le merece concebir ${ }^{10}$.
}

Esta escena es particularmente interesante, pues aúna misticismo y poesía en una síntesis en la que el Monte, el Prado y la Mies se lamentan de que ellos no reciban el efecto benefactor del rocío. La naturaleza plena funde, en ese lamento, el anhelo vivo y temporal del agua salvadora con un ansia de salud trascendental. Las espigas se duelen, el ganado perece de sed, las hojas se quejan y gimen, todo, en una gigantesca prosopopeya se eleva como un canto que sólo queda atemperado con la palabra de la Aurora que pide a la naturaleza el favor de ese día, el día de la concepción del hijo que también todos los elementos de la naturaleza demandan como salvación.

Después volverán las escenas de carácter «histórico» en el desarrollo del argumento. Gedeón repite el ruego acerca del milagro del maná, pero ahora invertido: el maná deberá regar todo, excepto el vellón, pues esa piel sólo una vez habrá de concebir. Después de satisfecha la prueba, Gedeón comenzará la marcha con todas las tribus, ordenando, no obstante, el Ángel, como en el texto bíblico, que se aparten los que no sean animosos, y luego los que sean demasiado animosos, pues la victoria ha de ser de la fe no de la fuerza. Estas escenas darán ocasión a unos jocosos chistes del gracioso Fará a costa de su pusilanimidad y del agua que tiene que beber. La batalla contra los madianitas tiene lugar dentro. La Idolatría describirá la derrota de Madián. Pero no es definitiva y el enemigo se retira a su campamento.

El quinto eje en el juego de perspectivas tiene lugar por medio de un sueño. El sueño, como sabemos, de raigambre bíblica, es uno de los elementos que utiliza frecuentemente Calderón para exponer la idea de premonición ${ }^{11}$. Esta vez son los enemigos Madián y Amalec los que han tenido un sueño, que explican a la pitonisa de Baal (la

10 Calderón de la Barca, La piel de Gedeón, vv. 1028-1031, pp. 141-142.

11 Rull, 2004, pp. 365-368. 
Idolatría) para que lo interprete. El sueño venía ya dado en el texto bíblico (Jueces, 7, 13-15), sólo que allí eran dos hombres anónimos quienes relataban el sueño de la derrota definitiva de Madián, el cual era oído por Gedeón y lo tomó como una profecía de su triunfo, mientras que el dramaturgo personaliza y especifica el contenido de ese sueño. En él se representa un pan reluciente en el cielo y una espada amenazante, que la Idolatría toma por el Sacramento y el castigo para ella misma. Gedeón también lo oye y lo interpreta favorablemente, mientras sus enemigos pelean entre sí. La Idolatría intenta quemar la mies, el monte y el prado sucesivamente, pero no puede, porque en todos ellos hay un misterio que no puede explicar.

Será precisamente en una nueva visión (sexto eje de perspectiva y nuevo punto de inflexión) donde, haciéndose pintura y teatro puros, se represente de nuevo la escena del Ángel con la Aurora (como en el segundo):

Ábrense las cuatro nubes y llueven las tres que primero no llovían, y la otra no, donde ha de estar la Aurora con el Ángel arrodillado, como quedaron cuando se cerró ${ }^{12}$.

El cuadro, que recuerda claramente a tantas pinturas sobre el tema de La Anunciación, por ejemplo la famosa de Fra Angelico, o la de Taddeo Gaddi, es una muestra de iconografia didascálica que nos invita claramente a relacionar la Aurora con la Virgen María y al Ángel arrodillándose ante ella, como en los mencionados cuadros. Incluso en bajorrelieves, como el de San Sovino en la catedral de Loreto, tenemos siempre la imagen del Ángel arrodillado ante la Virgen, cuando quizá por el texto bíblico esperaríamos la sumisión y, por tanto, la genuflexión de María ante el Ángel («he aquí la esclava del Señor»), que representa a Dios. No siempre esta actitud es la misma, como podemos observar en el recuento siguiente de algunas pinturas y grabados anteriores o contemporáneos de Calderón. En distintos autores puede verse cierta vacilación. Observamos que la mayor parte de los cuadros que representan La Anunciación desde Fra Angelico (1430-1432) tienden a representar a María en una posición ligeramente superior a la

12 Calderón de la Barca, La piel de Gedeón, p. 181. 
del Ángel, y a este genuflexo en una actitud de sumisión ${ }^{13}$. El contrapunto ligeramente posterior lo marca Rogier van der Weyden (1455), en donde el Ángel está notoriamente elevado y la Virgen arrodillada en un nivel inferior ${ }^{14}$. Cabría pensar que en los pintores de la escuela flamenca y alemana predomina esta última actitud. Sin embargo no siempre es así. El extremo más radical es el de Johannes Wierix (1549-1615), artista flamenco, quien realiza un grabado sobre el tema en el que el Ángel está totalmente suspendido en el aire y la Virgen arrodillada ante un escritorio y sobre su cabeza la paloma del Espíritu Santo y ángeles niños. Son innumerables las referencias posibles de diferentes Anunciaciones ${ }^{15}$. Aquí nos ceñiremos a unas cuantas que nos parecen más interesantes.

Matthias Grünewald, el más grande pintor alemán del siglo XVI, junto con Durero, es autor del maravilloso Retablo de Isenheim (1514), en cuya tabla lateral izquierda aparece una sorprendente Anunciación realizada en una capilla gótica, en donde el Ángel aparece notoriamente más elevado que la Virgen. Por el contrario, otro cuadro famoso del mismo tema, el de Leonardo da Vinci (entre 1470-1471), muestra a la Virgen en actitud sedente pero más elevada que el Ángel, quien está totalmente arrodillado. De Fra Filippo Lippi conservamos una notoria tabla sobre el tema, en donde la actitud de la Virgen es muy especial: aparte de que el Ángel está también totalmente arrodillado, ella parece salir, en una complicada postura, de una estancia, en posición totalmente erguida girando el busto hacia aquel. El Maestro de la Anunciación de Aix, cuyo nombre se debe precisamente al retablo de la Anunciación conservado en la catedral de Aix-en-Provence (h. 1443), muestra un gran equilibrio en las figuras, que están en actitud genuflexa a una misma altura aproximadamente, y, en la esquina superior izquierda, Dios Padre enviando un rayo de luz a la Virgen, dentro del cual puede verse un diminuto Niño Jesús. El Pinturicchio, realiza un fresco para Sta. Maria Maggiore en el que la Virgen está de pie frente a un atril con libro y el Ángel arrodillado a menor altura lógicamente.

13 Está realizada al fresco y se halla en el Museo Nacional de San Marcos de Florencia. Otra versión del propio Fra Angelico se encuentra en el Museo del Prado de Madrid.

${ }^{14}$ Se conserva en el Museo del Prado de Madrid.

${ }^{15}$ Ver las copiosas reproducciones de cuadros sobre el tema en el libro La Anunciación, 2004. 
Rafael realizó un cuadro con la Virgen sentada y el Ángel de pie casi corriendo en su llegada a ella, desmintiendo la idea de que la pintura italiana siempre trató el tema de la Anunciación desde la perspectiva de la superioridad jerárquico-iconográfica de la Virgen. Konrad Witz realiza una tabla al temple en 1440 (Nuremberg) en la que el equilibrio y la simplicidad se hermanan: el Ángel está inclinado, mientras que la Virgen, en actitud sedente, está a un nivel algo más bajo que aquél. La estancia es muy pobre y sin muebles ni adornos; es lo contrario del magnífico cuadro barroco de Francisco Rizi (16081685), contemporáneo de Calderón, donde una tímida Virgen arrodillada recibe la visita magnificente, en un paisaje abierto al exterior, de un ampuloso y bello Ángel sobre una nube más elevado que ella ${ }^{16}$. El Greco, en un soberbio cuadro, está más dentro de la tradición germánica, pues el Ángel está en una nube bastante elevado mientras que la Virgen, sedente, permanece ante una mesa a menor altura. Finalmente, Murillo presenta las figuras, en un cuadro de hacia 16551665, arrodilladas a una altura similar, algo más alta la Virgen, aunque realmente el centro del cuadro corresponde al Espíritu Santo en forma de paloma rodeado de angelitos típicos del autor.

Una cierta, llamémosle, «deificación» de María, o prevalencia suya sobre el ángel, pasó rápidamente a la iconografia y de esta a la propia concepción calderoniana. De ahí la presente acotación reveladora del auto a que hacemos referencia. En este breve repaso por la iconografia de la Anunciación anterior a Calderón, podemos observar que ya está estereotipada la escena, con lo cual era lógico que el dramaturgo reflejase, en su didascalia explícita, el espíritu y la fórmula del tópico, siguiendo la tradición latina "con el Ángel arrodillado» antes que la germánica, aunque, como ya hemos visto, no siempre la representación latina es uniforme. El cuadro que nos presenta el dramaturgo es, además de un soporte estructural, una culminación, pues coincide con el triunfo de Gedeón, y los gritos de victoria de sus partidarios: («Dentro. ¡Victoria por Gedeón!» ${ }^{17}$, personaje que es precisamente quien tiene la visión anticipadora de la Aurora, ante el asombro de la Idolatría, a quien explica el Ángel el misterio:

${ }^{16}$ Ver la magnífica ilustración de este en Díez Borque, 2000, p. 83.

17 Calderón de la Barca, La piel de Gedeón, v. 1647, p. 181. 


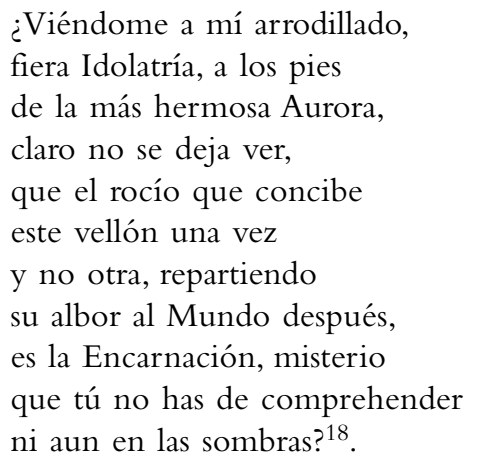

Aquí se demuestra claramente que Calderón tenía in mente la imagen de los cuadros sobre la Anunciación de estirpe esencialmente latina y católica. Implícitamente estaba en su sintética mente también la Encarnación, como sucedía en el cuadro, por ejemplo, del Maestro de la Anunciación de Aix, y como demuestra un texto del propio Calderón correspondiente a Las espigas de Ruth, una de cuyas acotaciones dice:

Ábrese el primero medio carro, $y$ vese el Sembrador en la misma acción que se vio al principio, $y$ dando vuelta, como dicen los versos, se ven en el reverso del otro medio carro una Niña, con manto azul, y un Ángel de rodillas, figurando lo mejor que se pueda un cuadro de encarnación ${ }^{19}$.

El texto que sigue es la prueba fehaciente de que Calderón identificaba la representación iconográfica del misterio de la Encarnación con lo que comúnmente entendemos por Anunciación. Este texto dice así:

SEMBRADOR

Sí ves

si de la figura pasas

a lo figurado.

LUCERO

¿Dónde

está?

18 Calderón de la Barca, La piel de Gedeón, vv. 1661-1671, p. 182.

19 Calderón de la Barca, Las espigas de Ruth, p. 149. 


\begin{tabular}{|c|c|}
\hline SEMBRADOR & $\begin{array}{l}\text { En esta tierra intacta, } \\
\text { que vendrá después de mí, } \\
\text { en quien siembre la palabra } \\
\text { de Dios mejor sembrador. }\end{array}$ \\
\hline DisCORDia & No veo nada. \\
\hline LUCERO & $\begin{array}{l}\text { No veo nada, } \\
\text { que sin duda este misterio } \\
\text { es el que Dios me recata } \\
\text { tanto, que toda mi vista, } \\
\text { ni mi ciencia no le alcanzan. }\end{array}$ \\
\hline SEMBRADOR & $\begin{array}{l}\text { Pues aunque tú no le veas, } \\
\text { diciendo está en voces altas: }\end{array}$ \\
\hline ÁNGEL & «Ave María, llena de gracia». \\
\hline MúSICA & «Ave María, llena de gracia», \\
\hline ÁNGEL & «Bendita tú eres». \\
\hline MÚSICA & «Llena de gracia». \\
\hline ÁNGEL & «Entre las mujeres». \\
\hline MÚSICA & «Llena de gracia» \\
\hline ÁNGEL & «Y bendito es el fruto de tus entrañas». \\
\hline Música & «Ave María, llena de gracia». \\
\hline NiÑA & $\begin{array}{l}\text { Esclava soy del Señor, } \\
\text { en mí su voluntad se haga. }\end{array}$ \\
\hline MÚSICA & «Ave María, llena de gracia» ${ }^{20}$. \\
\hline
\end{tabular}

La síntesis de la que hablamos se manifiesta de forma explícita en las siguientes tres acotaciones sucesivas: 1. «Descúbrese en el segundo carro un cuadro de la Encarnación», 2. «Descúbrese una Cruz en el tercer carro", y 3. «Descúbrese, en el cuarto carro, un cordero en el altar con un Cáliz y Hostia». Es la gradual apoteosis de la Eucaristía cuya evocación el autor trata de hacer plástica realidad. Con ella y con la pleitesía que da Gedeón y los demás a la fe por el sentido del oído, concluye el auto.

Como hemos visto, la construcción del mismo se apoya en seis ejes de perspectiva y en una poetización del maná en cuyo trasfondo late la simbología del vellón que el dramaturgo desdobla en dos realidades:

${ }^{20}$ Calderón de la Barca, Las espigas de Ruth, vv. 1603-1625, pp. 149-150. 
la Encarnación de Cristo y la Concepción de María, prefigurados en ese maná que es como el Espíritu Santo penetrando en el vellón (Forma eucarística) y en el seno de la Aurora (Virgen).Y así como la construcción del auto se fundamenta en elementos de perspectiva (sueños y visiones fundamentalmente), la poetización del maná recurre a toda una transformación de la naturaleza (nubes, montes, prados, mieses, corderos) en símbolos activos (algunos son auténticos personajes) de una alegorización habilísima que toma como base la historia de Gedeón, cuya propia dramatización queda asegurada por la inteligente estructuración de la misma, fundada en los puntos de inflexión que hemos analizado. Calderón puede ser fiel a la narración bíblica y a la simbología prefiguradora del Antiguo Testamento sin por ello dejar de recrear dramática y poéticamente el argumento y su propia alegorización.

Pero la benéfica lluvia del maná no solo se manifiesta poética y dramáticamente, como decimos, en La piel de Gedeón, sino también en los autos El viático cordero y La serpiente de metal, en los que utiliza su simbología para estructurar los acontecimientos, aunque de manera radicalmente distinta a este auto excepcional. En El viático cordero, por ejemplo, se describe pormenorizada y sucesivamente el éxodo de Moisés y los israelitas de Egipto (nacimiento de Moisés, la zarza ardiente, las plagas, el sacrificio del cordero y las puertas rociadas con su sangre para la identificación de sus habitantes, la salida de Egipto, el paso del Mar Rojo y la llegada a puerto; historia mezclada con las intervenciones chistosas del gracioso Libio, las explicaciones didáctico-simbólicas acerca del cordero, la dramatización de los acontecimientos, donde la Idolatría y Baal juegan un papel muy importante, los terremotos, las tribulaciones, el simbolismo del árbol, el hambre de los israelitas y el envío del maná, la tentación de los hombres, la caída de Zambrí y la salvación de Finés, y la coronación final de la eucaristía).

Lo importante de todo esto es cómo el autor ha organizado la materia argumental y simbólica en torno a varios motivos (el agua, el leño, el maná), que resume hacia el final del auto en una escueta y exotérica exposición:

BAAL

¿Qué sacramentos?

ÁNGEL $2^{\circ}$

Los que dijeron mis sombras...

ÁngeL $I^{\circ}$

Los que mis luces dijeron... 
ÁNGEL $2^{\circ}$

ÁNGEL $I^{\circ}$

ÁNGEL $2^{\circ}$
... desde el cordero a las aguas...

$\ldots$ desde las aguas al leño...

... y desde el leño al maná ${ }^{21}$.

De esta manera podemos comprobar cómo en este auto el maná se ofrece como coronación simbólico-eucarística de la Aurora, o amanecer de una nueva era, pues su inclusión en el texto, a través de toda la historia del éxodo, supone el punto final del hallazgo salvífico, simbolizado precisamente en ese maná que se transforma en elemento fundamental del auto, como auténtica apoteosis, al unirlo al don eucarístico. Así, frente a la estructura vertical en seis puntos de inflexión, articulados en forma de visiones y sueños de La piel de Gedeón, El viático cordero diseña su composición de manera horizontal y progresiva, en una sucesión de motivos que el propio autor enumera (como en los versos citados), para concluir en la culminación del maná.

La serpiente de metal reproduce el argumento del éxodo mosaico de la obra anterior, incluyendo los personajes de Idolatría y Belfegor (este en lugar de Baal), como contrapunto de Moisés, a quienes ahora acompañan, no solo Aarón, como en El viático cordero, sino también Josué, y las mujeres Céfora y María, quienes celebran con cantos de alabanza la salida de Egipto. En la obra, siguiendo de forma bastante literal algunos aspectos parciales del relato bíblico (Éxodo, 12-16, 32; y Números, 11-21) se describe el paso del Mar Rojo, las plagas, la matanza de los primogénitos y el rito del cordero, episodios que después se van dramatizando. La acción del peregrinaje a la tierra prometida se desarrolla con el enfrentamiento de la Idolatría y Belfegor contra Moisés y los suyos; a estos también se opondrán los siete Afectos desde dentro del campo mosaico. Las intrigas de la Idolatría conseguirán mover a Amalec contra los israelitas, pero Josué saldrá victorioso. Ante el desánimo de los israelitas un Ángel los llama a que despierten de su sueño y recobren ánimo para seguir su camino. Otro Ángel arroja desde el cielo el maná que todos comen, pero los Afectos dudan de que ese maná sea aliento de Dios, y proponen a Aarón como jefe pidiéndole un nuevo dios que los saque del desierto. Así, se reúnen materiales para hacer un ídolo que será un becerro alrededor del cual

${ }^{21}$ Calderón de la Barca, El viático cordero, p. 192. 
todos danzan. Josué se horroriza cuando lo ve. Moisés le golpea con una vara y el ídolo se hunde. Los Afectos siguen lamentándose y son presa de las serpientes. Ante sus lamentos, Moisés utilizará como antídoto una serpiente de metal que curará a todos los que la miran. Al final el autor acude otra vez a la virtud del maná como símbolo eucarístico y coronación del auto, pero el recurso ya estará contrarrestado por la imagen de la serpiente de metal, cuya explicación alegórica queda un tanto imprecisa, quizá por haberse limitado el dramaturgo a seguir el relato evangélico, en este caso con pocos elementos estructurales realmente innovadores. Evidentemente entre ellos está la visión de los ángeles arrojando el maná a los israelitas. Este hubiera sido un final en clímax adecuado, pero el autor ha preferido seguir el texto bíblico como mera narración histórica que es. Y aquí se rompe la posible estructura coherente desde el punto de vista puramente dramático, pues un auto no es nunca, ni puede ser, una simple narración. No obstante, Calderón intenta una explicación simbólica del áspid en estos términos:

IDOLATRÍA Si tan gran sujeto quieres que signifique, ¿no fuera bien poner otra figura menos horrorosa que esa, que es un áspid?

MOISES

No, porque

para sanar las dolencias del que, mordido del áspid, al pecador se semeja, no siendo él el pecador, convendrá que lo parezca ${ }^{22}$.

Parece que en la virtud curativa de la serpiente se quiere simbolizar la apariencia humana de Cristo como hombre, pero sin el pecado de este. Así, quedaría resuelta la simbología cristológica de la serpiente de metal del Antiguo Testamento, pero se introduciría un factor que no culmina la apoteosis, pues esta se concede de nuevo al maná, con lo que el papel de la serpiente que da entidad al auto queda difuminado o contrarrestado, como decíamos antes.

22 Calderón de la Barca, La serpiente de metal, p. 38. 
Por todo ello, de los tres autos que tratan el tema del maná como símbolo eucarístico, este, por su linealidad y su ambiguo clímax final, nos parece el menos interesante como obra de arte, mientras que consideramos más conseguido, con mucho, el de La piel de Gedeón, por su más complejo simbolismo, por su estructura compositiva a base de elementos de perspectiva, con una culminación apoteósica perfectamente graduada, y por la gran fuerza poética de su alegoría y de las imágenes de la naturaleza que de ella se derivan. 


\section{Bibliografía}

Arellano, I., Diccionario de los autos sacramentales de Calderón, Pamplona / Kassel, Universidad de Navarra / Reichenberger, 2000.

- Estructuras dramáticas y alegóricas en los autos de Calderón, Pamplona / Kassel, Universidad de Navarra / Reichenberger, 2001.

Bachelard, G., El aire y los sueños, México, Fondo de Cultura Económica, 1958.

Calderón de la Barca, P., La piel de Gedeón, ed. A. Armendáriz, Pamplona / Kassel, Universidad de Navarra / Reichenberger, 1998.

- Las espigas de Ruth, ed. C. Buezo, Pamplona / Kassel, Universidad de Navarra / Reichenberger, 2006.

- El viático cordero, ed. J. M. Escudero, Pamplona / Kassel, Universidad de Navarra / Reichenberger, 2007.

- La serpiente de metal, ed. P. de Pando y Mier, en Autos sacramentales, alegóricos y historiales, 1717, t. II, pp. 6-39.

Díez Borque, J. M., Calderón de la Barca. Verso e imagen, Madrid, Comunidad de Madrid, 2000.

La Anunciación, La, trad. C. Palacios Gasós, Barcelona, PHAIDON, 2004.

Orozco DíAz, E., El teatro y la teatralidad del Barroco, Barcelona, Planeta, 1969.

- «Sentido de continuidad espacial y desbordamiento expresivo en el teatro de Calderón. El soliloquio y el aparte», en Calderón. Actas del Congreso Internacional sobre Calderón y el teatro Español del Siglo de Oro, ed. L. García Lorenzo, Madrid, CSIC, 1983, t. I, pp. 125-164.

PArker, A. A., Los autos sacramentales de Calderón de la Barca, Barcelona, Ariel, 1983.

Rull, E., Arte y sentido en el universo sacramental de Calderón, Pamplona / Kassel, Universidad de Navarra / Reichenberger, 2004. 
